\title{
Polyphyllin VII suppresses cell proliferation, the cell cycle and cell migration in colorectal cancer
}

\author{
$\mathrm{CHENG} \mathrm{SONG}^{1^{*}}, \mathrm{BO}^{\mathrm{PAN}}{ }^{2 *}, \mathrm{XIAO} \mathrm{YANG}^{3}$ and $\mathrm{WEI} \mathrm{TANG}^{2}$ \\ ${ }^{1}$ Department of Chinese Medicine, Hunan Cancer Hospital, The Affiliated Cancer Hospital of Xiangya School of Medicine, \\ Central South University; ${ }^{2}$ First Department of Oncology, Hunan Academy of Traditional Chinese Medicine Affiliated Hospital; \\ ${ }^{3}$ Department of Oncology, The First Hospital of Hunan University of Chinese Medicine, Changsha, Hunan 410013, P.R. China
}

Received December 11, 2019; Accepted August 18, 2020

DOI: $10.3892 / \mathrm{ol} .2020 .12286$

\begin{abstract}
Colorectal cancer (CRC) is one of the most common types of human cancer. However, there is still an urgent need to identify novel treatment strategies for CRC. The present study aimed to validate the potential antitumor effects of polyphyllin VII in CRC. The present study revealed that polyphyllin VII could significantly inhibit CRC proliferation and induce cell cycle arrest and apoptosis. Moreover, the anti-metastatic effect of polyphyllin VII in CRC cells was implicated. Microarray analysis identified that polyphyllin VII could affect multiple protein coding genes and non-coding RNAs. Bioinformatics analysis revealed that polyphyllin VII regulated multiple pathways in CRC, including 'ER to Golgi vesicle-mediated transport', 'response to cAMP', 'Ras protein signal transduction', 'metabolic pathways', 'MAPK signaling pathway' and 'cell cycle'. Protein-Protein Interaction network analysis identified a series of key polyphyllin VII-regulating genes in $\mathrm{CRC}$, including ribonucleoside-diphosphate reductase subunit M2, structural maintenance of chromosomes protein 4 and DNA replication licensing factor MCM4. Finally, the present results demonstrated that these key polyphyllin VII-regulating genes were dysregulated in CRC. Taken together, these results indicated that polyphyllin VII could be a novel antitumor drug for the treatment of CRC.
\end{abstract}

\section{Introduction}

Colorectal cancer (CRC), accounts for $\sim 10 \%$ of all tumor-related deaths, is the third most common type of cancer

Correspondence to: Professor Wei Tang, First Department of Oncology, Hunan Academy of Traditional Chinese Medicine Affiliated Hospital, 58 Lushan Road, Changsha, Hunan 410013, P.R. China

E-mail: tangwei868688@163.com

${ }^{*}$ Contributed equally

Key words: polyphyllin VII, proliferation, cell cycle, migration, colorectal cancer worldwide $(1,2)$. Despite advances in diagnostic and therapeutic strategies, the prognosis of patients with CRC remains poor with high 5-year mortality (3). Oxaliplatin in combination with 5-fluorouracil and leucovorin is the first-line chemotherapeutic strategy for CRC, which functions as a DNA transcription and replication suppressor by forming platinum-DNA adducts (4). Oxaliplatin resistance commonly contributes to the failure of CRC therapy and worse clinical outcomes for patients with $\mathrm{CRC}$. Thus, there is an urgent need to identify novel anticancer drugs for CRC.

Polyphyllin, which is derived from Paris polyphyllin, has been used as a clinical drug in China (5). In previous years, polyphyllin was reported to be a potential anticancer drug in numerous types of human cancers, including breast cancer, non-small cell lung cancer and acute myeloid leukemia $(6,7)$. Recently, polyphyllin VII was found to have anticancer activity and be involved in inhibiting cancer growth, suppressing cancer cell metastasis, inducing cell cycle arrest and apoptosis in cancer cells (8-10). Chen et al (11) found that polyphyllin VII suppressed cell growth and induced autophagy in nasopharyngeal cancer via AKT signaling. Zhang et al (12) reported that polyphyllin VII could affect mitogen-activated protein kinase (MAPK) signaling and mitochondrial dysfunction to promote cell apoptosis in liver cancer cells. Although the antitumor activities of polyphyllin VII has been demonstrated in other types of cancer, the effects of polyphyllin VII on CRC progression and its underlying mechanisms remain unclear.

The present study aimed to determine the potential antitumor effects of polyphyllin VII in CRC. The effects of polyphyllin VII on CRC proliferation, cell cycle, apoptosis and migration were evaluated. Microarray analysis was performed to identify downstream targets of polyphyllin VII in CRC. The present study showed that polyphyllin VII could be a potential novel therapeutic drug for CRC.

\section{Materials and methods}

Cell culture and treatment. The human CRC HCT116 cell line was obtained from American Type Culture Collection. Cells were cultured in RPMI-1640 medium with $10 \%$ FBS (both Thermo Fisher Scientific, Inc.) and $100 \mathrm{U} / \mathrm{ml}$ penicillin-streptomycin at $37^{\circ} \mathrm{C}$ in a humidified atmosphere containing $5 \% \mathrm{CO}_{2}$. 
Cell viability assay. Cell Counting Kit-8 (CCK-8; Dojindo Molecular Technologies, Inc.) assay was used to detect the effects of polyphyllin VII (Chengdu Must Bio-Technology Co., Ltd.) on CRC cell viability, according to the manufacturer's instructions. Briefly, 1×10 ${ }^{4}$ HCT116 cells/well were seeded into 96-well plates. Subsequently, $0.9197 \mu \mathrm{g} / \mathrm{ml}$ polyphyllin VII was added and cells were incubated at $37^{\circ} \mathrm{C}$ for 5 days. Cultured HCT116 cells were incubated for $72 \mathrm{~h}$ in the presence of vehicle or polyphyllin VII at the indicated doses $(0.1$, $0.2,0.4,0.6,0.8,1.0,1.2,1.4,2.0$ and $5 \mu \mathrm{g} / \mathrm{ml})$. At each time point (days 1, 2, 3, 4 and 5), $10 \mu \mathrm{l} \mathrm{CCK-8} \mathrm{solution} \mathrm{was} \mathrm{added}$ to the cells. Following $2 \mathrm{~h}$ of incubation, the absorbance was detected at a wavelength of $450 \mathrm{~nm}$.

Cell cycle assay. Following polyphyllin VII treatment, HCT116 cells were collected and washed with PBS. Subsequently, cells $\left(1 \times 10^{6}\right)$ were treated with $0.03 \%$ Triton X-100 for $15 \mathrm{~min}$, and stained with propidium iodide (PI; $50 \mathrm{ng} / \mathrm{ml}$ ) and $80 \mu \mathrm{g} / \mathrm{ml}$ ribonuclease A (RNAse; Gibco; Thermo Fisher Scientific, Inc.) at room temperature for $15 \mathrm{~min}$. Cell cycle distribution was detected using a flow cytometer (FACSCalibur; BD Biosciences) and analyzed using ModFit 5.0 software (Verity Software House, Inc.).

Annexin V/PI double staining. The effects of polyphyllin VII on CRC cell apoptosis were determined using the Annexin V-FITC/PI apoptosis detection kit (EMD Millipore), according to the manufacturer's instructions. Briefly, cells were washed three times with PBS and resuspended in 1X binding buffer provided by the apoptosis kit. Subsequently, $2 \mu \mathrm{g} / \mathrm{ml}$ Annexin V-FITC and $2.5 \mu \mathrm{g} / \mathrm{ml}$ PI were added to the $1 \times 10^{6}$ cells. Following incubation in the dark for $15 \mathrm{~min}$, the early and late apoptosis statuses were analyzed using a flow cytometer, using FACSCalibur software (BD Biosciences). Apoptotic cells were subsequently analyzed via flow cytometry, using MoFlo XDP (Beckman Coulter, Inc.).

Colony formation assay. The colony formation assay was conducted according to Chen et al (11). Briefly, $1 \times 10^{4}$ HCT116 cells/well were seeded into a six-well plate. At $24 \mathrm{~h}$ later, $0.9197 \mu \mathrm{g} / \mathrm{ml}$ of polyphyllin VII were added to the cells and incubated at $37^{\circ} \mathrm{C}$ for 2 weeks. After 2 weeks, colonies (>50 cells) were stained with $0.3 \%$ crystal violet solution.

Wound healing assay. A total of $1 \times 10^{6}$ HCT116 cells/well were seeded into a six-well plate. When cell confluency reached $\sim 80 \%$, a scratch was created in the cell monolayer using a sterile micropipette tip. The detached cells were then washed with PBS. Then, the RPMI-1640 medium (Thermo Fisher Scientific, Inc.) was replaced with $1 \mathrm{ml}$ fresh RPMI 1640 medium without FBS. The extent of wound healing was observed at 0,8 and $30 \mathrm{~h}$. Images were captured in five randomly selected fields using an inverted microscope. Migration ability was determined by calculating the change in uncovered area between 0 and $24 \mathrm{~h}$ using MetaMorph software (MetaMorph Inc.).

Transwell assay. The invasion assay was performed using Matrigel $^{\circledR}$ (BD Biosciences), which was used in $8-\mathrm{mm}$ pore size Transwell plates (Corning, Inc.). A total of $5 \times 10^{4}$ HCT116 cells, cultured in RPMI-1640 medium with $2 \%$ FBS, were seeded into the upper chamber. In addition, RPMI-1640 with $10 \%$ FBS was added to the bottom chamber. Following incubation for $72 \mathrm{~h}$ at $37^{\circ} \mathrm{C}$, the cells were fixed with a $4 \%$ paraformaldehyde solution for $30 \mathrm{~min}$ at room temperature, followed by rinsing with PBS and staining with a $0.5 \%$ crystal violet dye solution for $10 \mathrm{~min}$ at room temperature. Subsequently, the cell counting was performed with a light microscope at x200 magnification.

Western blot analysis. Cells were lysed with RIPA lysis buffer (Applygen Technologies, Inc.). The BCA assay kit (Sangon Technology) was used to detect the protein concentration. Proteins (35 $\mu \mathrm{g} /$ lane) were subjected to $10 \%$ SDS-PAGE, and then subsequently transferred onto a PVDF membrane (EMD Millipore). Membranes were then incubated with 5\% non-fat milk for $1 \mathrm{~h}$ at room temperature, and stained with primary antibodies against ribonucleoside-diphosphate reductase subunit M2 (RRM2; 1:1,000; cat. no. ab172476; Abcam), Bax (1:1,000; cat. no. ab32503; Abcam), Bcl-2 (1:1,000; cat. no. ab59348; Abcam), structural maintenance of chromosomes protein 4 (SMC4; 1:1,000; cat. no. HPA029449; Sigma-Aldrich; Merck KGaA), cleaved caspase-3 (1:1,000; cat. no. 9661S; Cell Signaling Technology, Inc.) and anti-GAPDH (1:1,000; cat. no. sc-32233; Santa Cruz Biotechnology, Inc.) at $4^{\circ} \mathrm{C}$ overnight. Subsequently, the membrane was washed three times in TBS with 5\% Tween-20, and then incubated with horseradish peroxidase-conjugated anti-rabbit (cat. no. IH-0011; 1:5,000 dilution) and anti-mouse (cat. no. IH-0031; 1:5,000 dilution) (both Beijing Dingguo Changsheng Biotechnology Co., Ltd.) antibodies for $1 \mathrm{~h}$ at room temperature. Finally, the membrane was visualized with Enhanced Chemiluminescence Plus reagents (Thermo Fisher Scientific, Inc.). Protein band density was normalized to the corresponding GAPDH density.

Microarray and gene expression analysis. Gene expression profiling was analyzed using the PrimeView ${ }^{\mathrm{TM}}$ Human Gene Expression Arrays (Affymetrix; Thermo Fisher Scientific, Inc.), as described previously (13); the CEL-files of the raw data were obtained by Affymetrix GeneChip ${ }^{\circledR}$ Command Console ${ }^{\circledR}$ v1.0 Software (Affymetrix; Thermo Fisher Scientific, Inc.). Total RNA was extracted from HCT116 cells using TRIzol reagent 3 days after $0.9197 \mu \mathrm{g} / \mathrm{ml}$ polyphyllin VII and control treatment (DMSO) at $37^{\circ} \mathrm{C}$ for 3 days. RNA quantity and quality were assessed with a NanoDrop ${ }^{\text {TM }} 2000$ spectrophotometer (Thermo Fisher Scientific, Inc.) and an Agilent Bioanalyzer 2100. Briefly, reverse transcription, cDNA synthesis, and labeling were all performed using the GeneChip 3' IVT Expression kit (Thermo Fisher Scientific, Inc.). Microarray hybridization, washing and staining were carried out using the GeneChip Hybridization Wash and Stain kit (Thermo Fisher Scientific, Inc.).

The limma method in Bioconductor (version 3.38.3; http://www.bioconductor.org) was used to identify the genes that were differentially expressed between the two groups (14). Genes with an adjusted $\mathrm{P}<0.05$ after FDR correction and a fold-change of $>2$ or $<0.5$ were considered as differentially expressed genes (DEGs).

GO and KEGG pathway analyses. Database for Annotation, Visualization and Integrated Discovery (DAVID) 6.8 
A

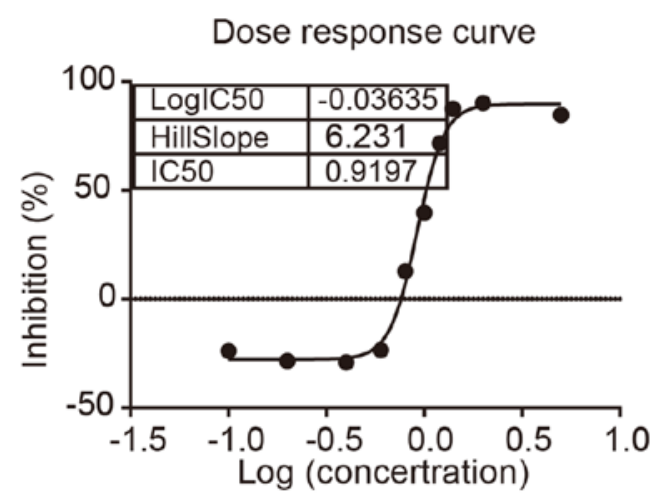

C

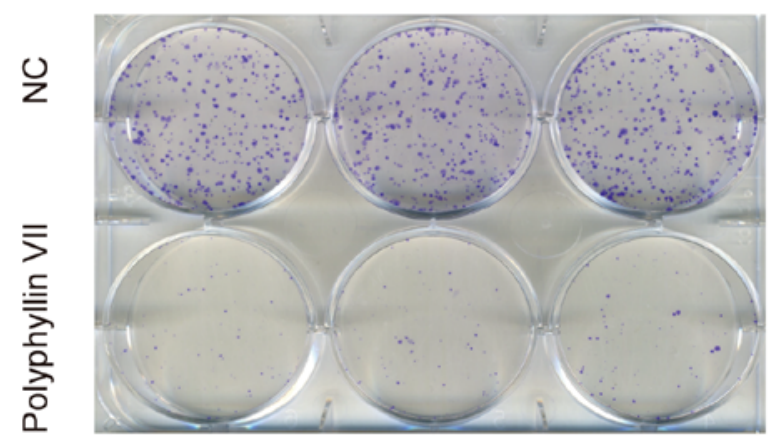

B

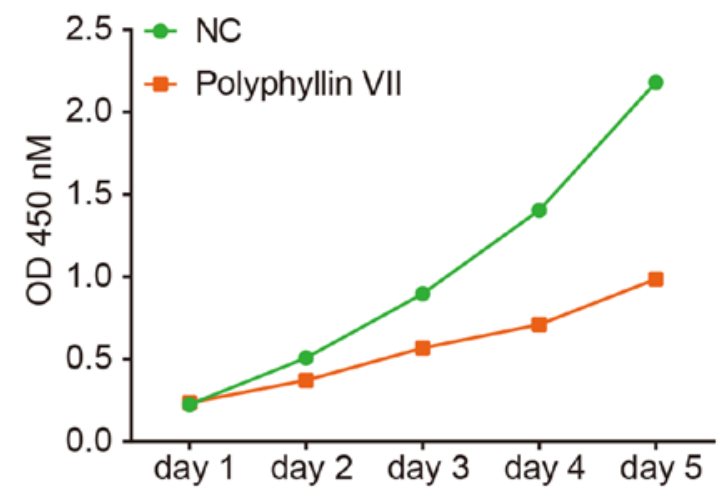

D

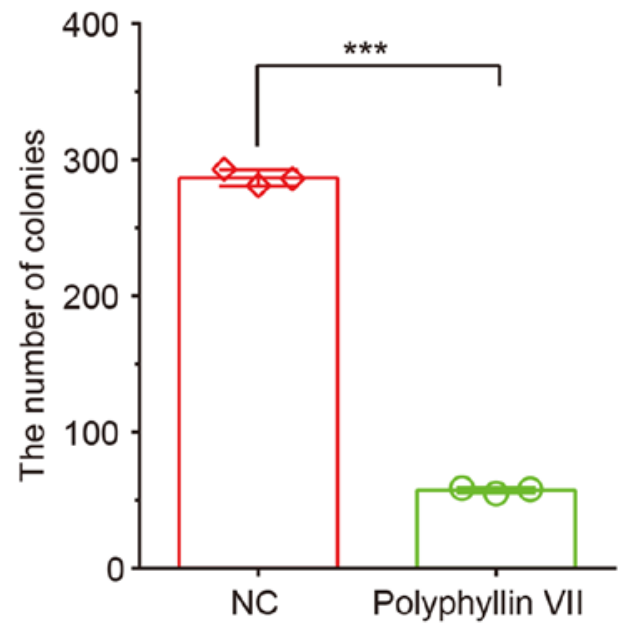

Figure 1. Polyphyllin VII suppresses CRC proliferation. (A and B) Cell Counting Kit-8 assay showed polyphyllin VII suppressed HCT116 cell proliferation. $(\mathrm{C}$ and $\mathrm{D})$ The colony number was suppressed by Polyphyllin VII treatment in HCT116 cells. Data are presented as the mean \pm SD ( $=3$ ). ${ }^{* * *} \mathrm{P}<0.001$. NC, negative control; CRC, colorectal cancer.

(http://david.abcc.ncifcrf.gov/) is an online platform that is used for gene annotation, visualization and integrated discovery (15). Gene Ontology (GO) (16) and Kyoto Encyclopedia of Genes and Genomes (KEGG) (17) pathway enrichment analyses were implemented with the DAVID database. Using this comprehensive tool, the biological meaning behind the DEGs can be understood more quickly and effectively. $\mathrm{P}<0.05$ indicated a statistically significant difference.

Protein-protein interaction (PPI) network. The Search Tool for the Retrieval of Interacting Genes (STRING, http://string-db. org) database was used to construct the PPI network (18). A confidence score $\geq 0.9$ was set as the cut-off criterion, and disconnected nodes were excluded from the network. CytoHubba (19) and Molecular Complex Detection (MCODE) (20) in Cytoscape 3.5.1 (21) were performed to identify hub genes and significant modules of the PPI network. The filter conditions were as follows: Degree cut-off $\geq 2$ and nodes with edges $\geq 2$-core.

Gene expression profiling interactive analysis (GEPIA). The present study used GEPIA (22) dataset to analyze the expression levels of DEGs after polyphyllin VII treatment in order to explore the differential expression and its effect on the prognosis of patients with rectum adenocarcinoma (READ) and colon adenocarcinoma (COAD).

Statistical analysis. Each experiment was performed at least three times in the present study. Statistical analysis was conducted using SPSS 13.0 software (SPSS, Inc.). Statistical significance between two groups was determined using student's t-test. $\mathrm{P}<0.05$ was considered to indicate a statistically significant difference.

\section{Results}

Polyphyllin VII inhibits CRC cell proliferation and colony formation. The effects of polyphyllin VII on CRC proliferation were first examined using a CCK- 8 assay. As shown in Fig. 1, compared with the control group, polyphyllin VII treatment resulted in a significant reduction in HCT116 cell viability. The $\mathrm{IC}_{50}$ at $72 \mathrm{~h}$ was $0.9197 \mu \mathrm{g} / \mathrm{ml}$, which was the dose used for further experiments (Fig. 1A).

A CCK-8 assay was further used to evaluate the effect of polyphyllin VII treatment on CRC cell proliferation. The results showed that polyphyllin VII treatment notably inhibited HCT116 cell proliferation compared with the control group 


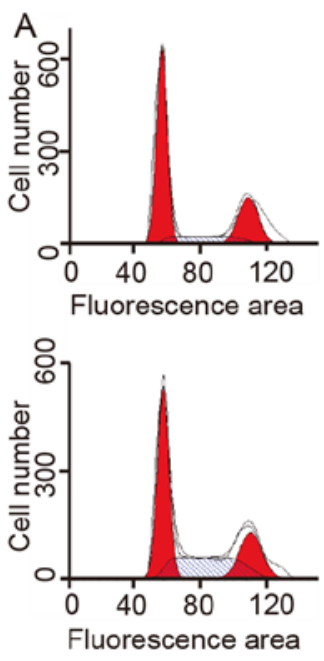

B

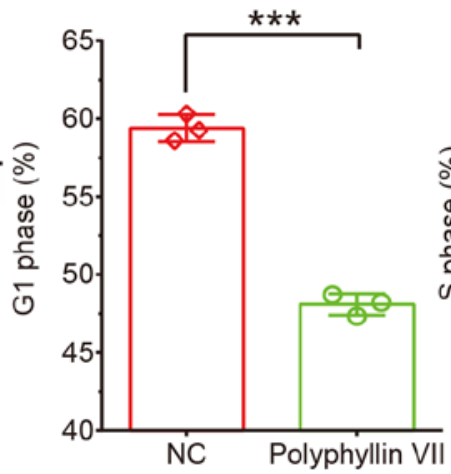

C

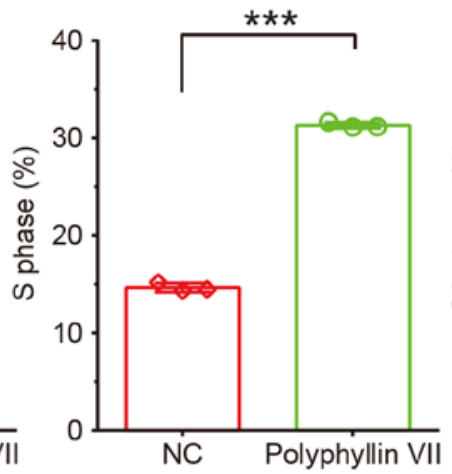

D

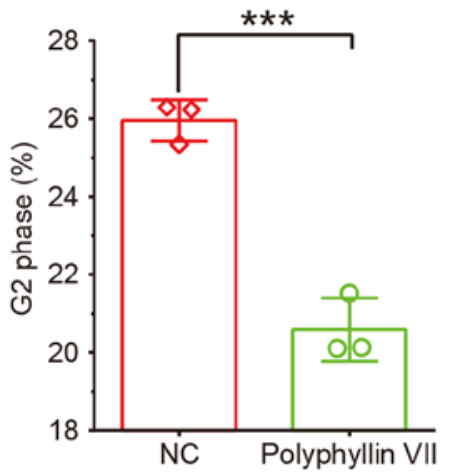

E

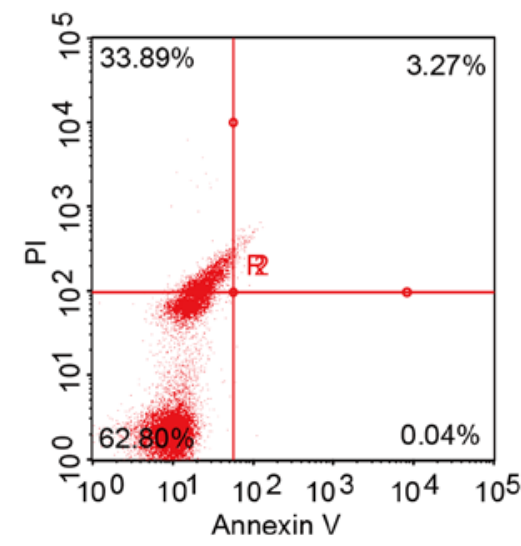

F

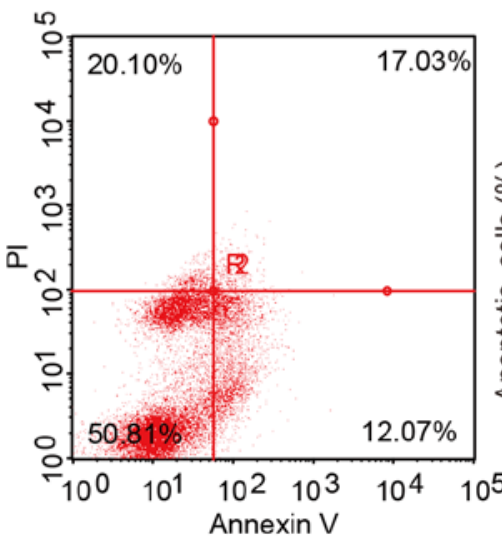

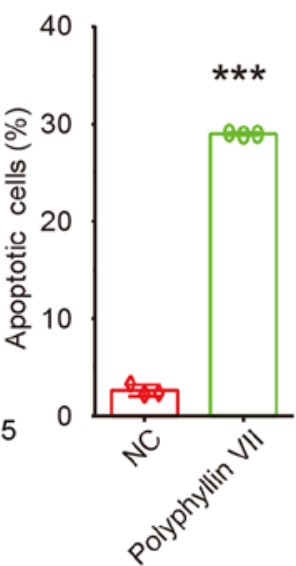

$\bar{\Sigma}$

G

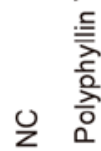

Bcl-2

GAPDH

Bax

GAPDH

Pro-

Caspase-3

Cleaved

Caspase-3 SMC4

GAPDH

Figure 2. Polyphyllin VII induces CRC cell cycle arrest and apoptosis. (A) Polyphyllin VII induced CRC cell cycle arrest, as determined using a FACScalibur flow cytometer. The (B) G1, (C) S and (D) G2 phase analysis results are presented as the mean \pm SD (n=3). (E) Polyphyllin VII induced CRC cell apoptosis, as determined using a FACScalibur flow cytometer. (F) The cell apoptosis analysis results are presented as the mean \pm SD $(n=3)$. (G) The protein expression levels of cleaved caspase-3, Bcl-2, Bax and SMC4 were detected in HCT116 cells following polyphyllin VII treatment. ${ }^{* * * *} \mathrm{P}<0.001$ vs. NC. NC, negative control; CRC, colorectal cancer; SMC4, structural maintenance of chromosomes protein 4.

(Fig. 1B). In addition, polyphyllin VII treatment significantly suppressed HCT116 cell colony formation. The relative colony number in the polyphyllin VII treatment group decreased by $85 \%$ in HCT116 cells (Fig. 1C and D).

Polyphyllin VII induces cell cycle arrest and apoptosis in CRC cells. In order to explore how polyphyllin VII suppresses CRC cell proliferation, the cell cycle of CRC cells after polyphyllin VII treatment was analyzed using flow cytometry. The results showed that polyphyllin VII could significantly induce cell cycle arrest in $\mathrm{S}$ phase, which led to a significant increase of cells in $\mathrm{S}$ phase, but a significant decrease of cells in the G1 and $\mathrm{G} 2$ phases (Fig. 2A-D).

The effect of polyphyllin VII on CRC cell apoptosis was then assessed using flow cytometry. At 3 days post-incubation, the number of apoptotic HCT116 cells in the polyphyllin VII group increased by $50 \%$ compared with the control group (Fig. 2E and F). Then, the protein expression levels of pro caspase-3, cleaved caspase-3, Bcl-2 and Bax were detected in CRC cells following polyphyllin VII treatment. A notable increase in the expression levels of cleaved caspase- 3 and Bax were observed (Fig. 2G). However, no significant changes in the expression levels of pro caspase 3 and $\mathrm{Bcl}-2$ were observed in CRC cells after polyphyllin VII treatment (Fig. 2G).

Polyphyllin VII suppresses CRC invasion. Subsequently, the effects of polyphyllin VII treatment on CRC cell migration were determined using a wound healing assay. Cells treated with polyphyllin VII showed lower wound healing ability (Fig. 3A and B). A Transwell assay was also performed to validate the present findings. As shown in Fig. 3, the number of polyphyllin VII-treated HCT116 cells that passed through the Transwell membrane significantly decreased compared with the control group (Fig. 3C and D). The results indicated that polyphyllin VII could suppress CRC metastasis.

Identification of polyphyllin VII-regulated DEGs in CRC. The present study screened differentially expressed mRNAs and long non-coding RNAs (lncRNAs) following polyphyllin VII treatment in CRC using microarray analysis. Genes with a 
A
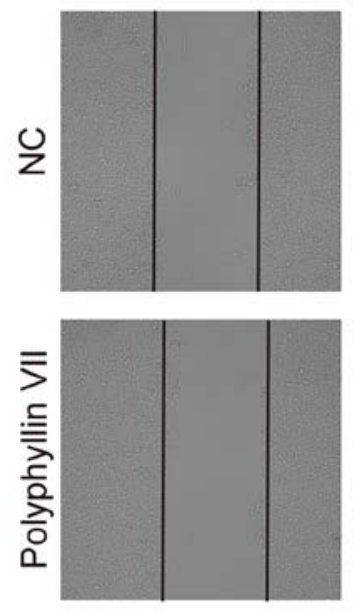

C
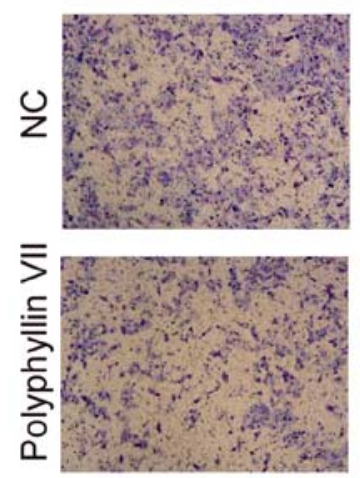
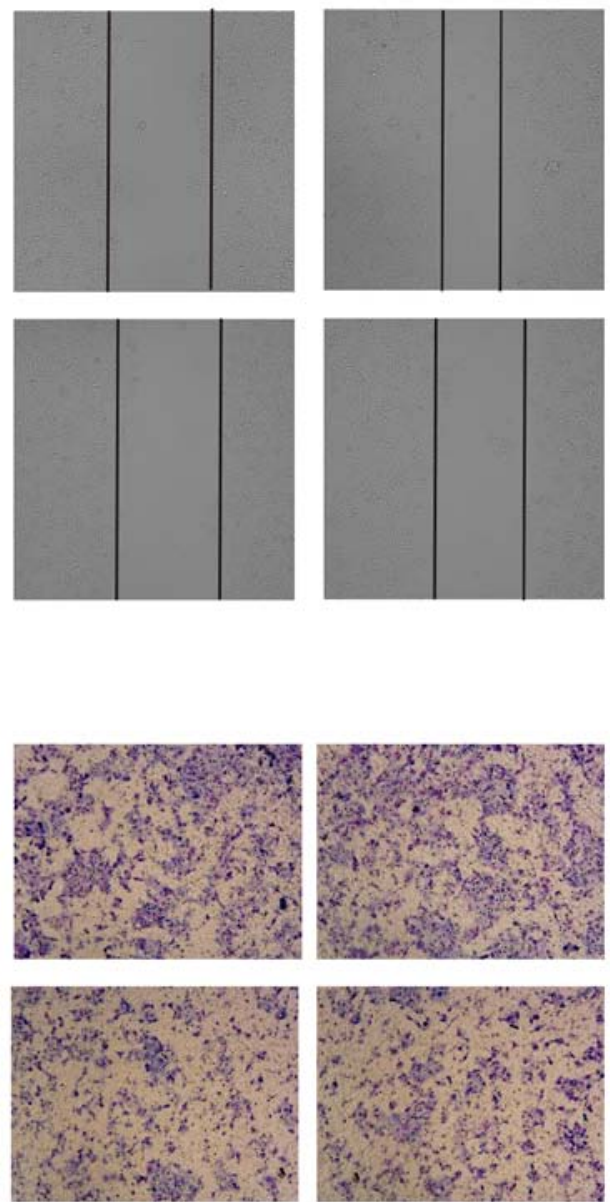

B

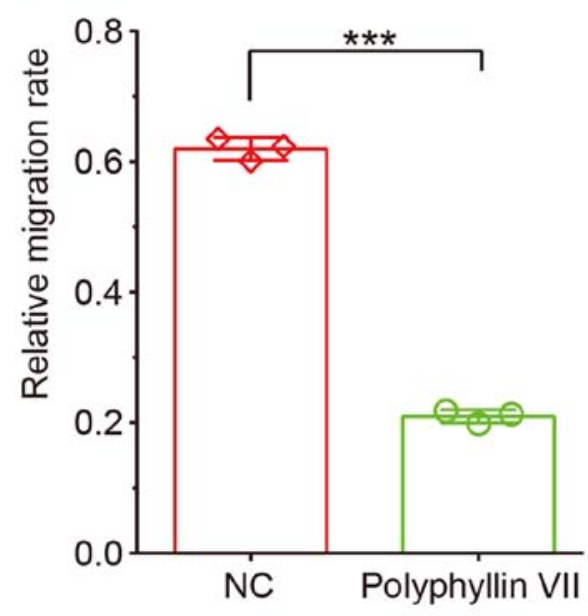

D

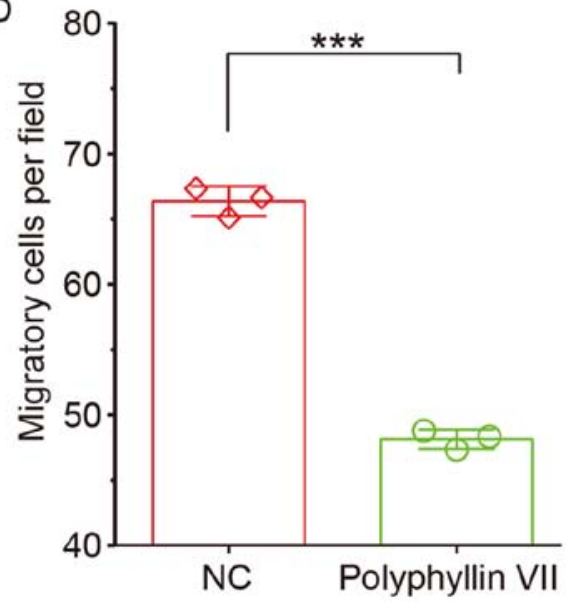

Figure 3. Polyphyllin VII suppresses colorectal cancer cell migration. (A) Representative images of wound healing assays. HCT116 cells treated with polyphyllin VII were subjected to wound healing migration assays. Magnification, x200. (B) Relative migration rate. (C) Representative images of Transwell assays. Magnification, x200. HCT116 cells treated with polyphyllin VII were subjected to Transwell assays. (D) Number of migratory cells per field. ${ }^{* * *} \mathrm{P}<0.001$. NC, negative control.

fold-change in expression of $\geq 2.0$ and $\mathrm{P}<0.05$ between control and polyphyllin VII-treated samples were identified to be differentially expressed.

As shown in Fig. 4, 469 mRNAs were detected to be differentially regulated by a fold-change $\geq 2.0$, among which 411 mRNAs were upregulated, while 511 mRNAs were downregulated (Fig. 4A). The top 10 differentially expressed mRNAs are listed in Table I. A total of 347 upregulated lncRNAs and 1,765 downregulated lncRNAs were observed after polyphyllin VII treatment in CRC samples (Fig. 4B). Several well-known lncRNAs, such as urothelial cancer associated 1 (UCA1), nuclear enriched abundant transcript 1 (NEAT1), metastasis associated lung adenocarcinoma transcript 1 (MALAT1) and ZNFX1 antisense RNA 1 were identified to be polyphyllin VII targets. The top 10 differentially expressed 1 ncRNAs are listed in Table II. Hierarchical clustering showed differentially expressed mRNAs and lncRNAs in CRC.

GO and KEGG analysis of polyphyllin VII-regulated genes in $C R C$. Furthermore, GO and KEGG analyses were performed to identify polyphyllin VII targets. GO analysis showed that polyphyllin VII targets were significantly associated with multiple biological processes, including 'ER to Golgi vesicle-mediated transport', 'heart development', 'regulation of cellular response to heat', 'cholesterol biosynthetic process via lathosterol', 'response to cAMP', 'Ras protein signal transduction', 'phosphatidic acid biosynthetic process', 'epidermal growth factor receptor signaling pathway', 'insulin receptor signaling pathway', 'positive regulation of transcription, DNA-templated', 'peptidyl-serine phosphorylation', 'cholesterol biosynthetic process', 'anaphase-promoting complex-dependent catabolic process', 'G1/S transition of mitotic cell cycle', 'phosphatidylinositol-mediated signaling', 'regulation of ubiquitin-protein ligase activity involved in mitotic cell cycle', 'COPII vesicle coating' and 'protein localization' (Fig. 4C).

KEGG pathway analysis revealed that polyphyllin VII target genes were enriched in 'metabolic pathways', 'protein processing in endoplasmic reticulum', 'oxidative phosphorylation', 'epithelial cell signaling in Helicobacter pylori infection', 'legionellosis', 'MAPK signaling pathway', 'HTLV-I infection', 'Alzheimer's disease', 'Huntington's disease', 'estrogen signaling pathway', 'Parkinson's disease', 'Epstein-Barr virus infection', 'cell cycle', 'ErbB signaling pathway' and 'TNF signaling pathway' (Fig. 4D). 
A

NC

mRNA
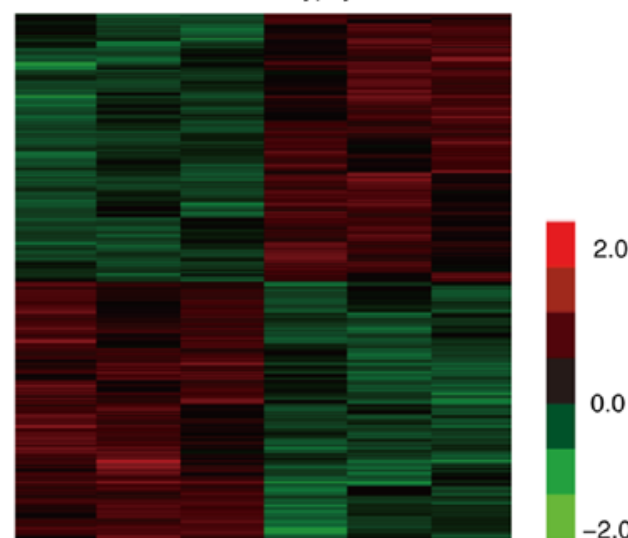

B

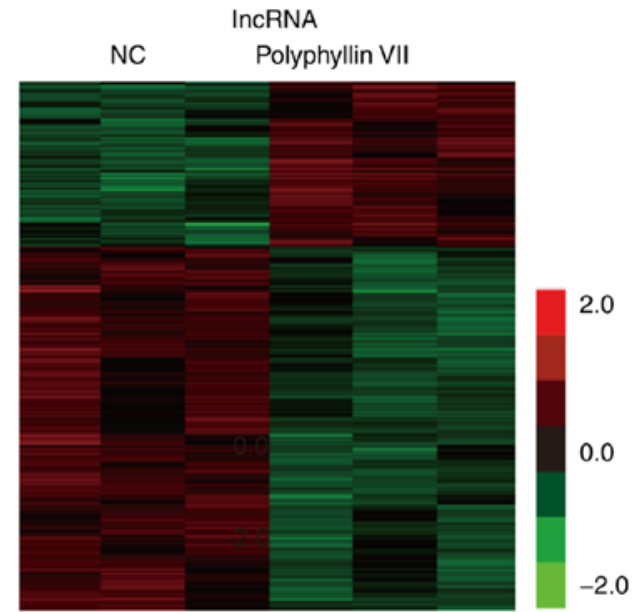

C

Positive regulation of transcription, DNA-templated ER to Golgi vesicle-mediated transport Heart development Peptidyl-serine phosphorylation Regulation of cellular response to heat Phosphatidylinositol-mediated signaling

G1/S transition of mitotic cell cycle Anaphase-promoting complex-dependent catabolic process Insulin receptor signaling pathway

Ras protein signal transduction

Protein localization

COPII vesicle coating

Epidermal growth factor receptor signaling pathway

Response to cAMP

Cholesterol biosynthetic process

Phosphatidic acid biosynthetic process Regulation of ubiquitin-protein ligase activity involved in Cholesterol biosynthetic process via lathosterol mitotic cell cycle

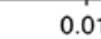

0.01

D

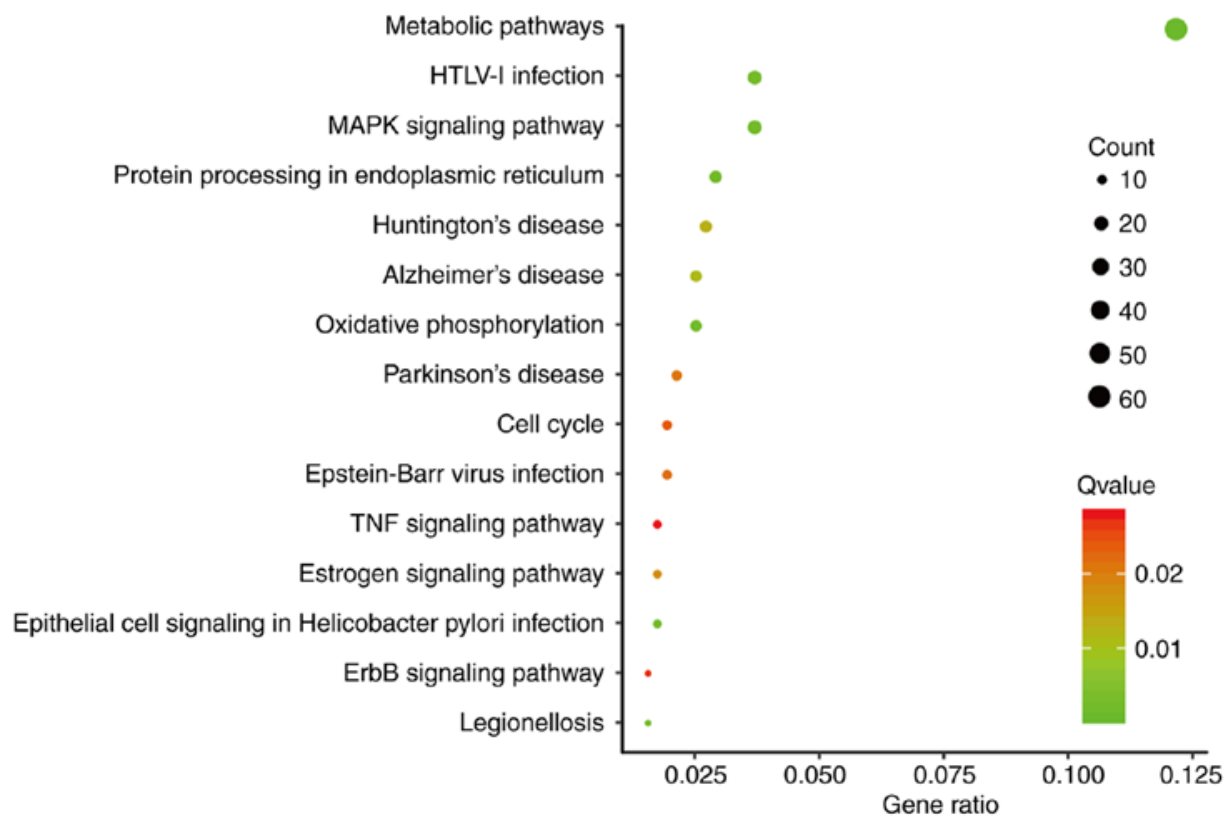

Figure 4. Identification of downstream targets of polyphyllin VII in CRC. Identification of differently expressed (A) mRNAs and (B) lncRNAs in CRC cells after treatment with polyphyllin VII. (C) Gene Ontology and (D) Kyoto Encyclopedia of Genes and Genomes pathway analysis of downstream targets of polyphyllin VII in CRC. NC, negative control; CRC, colorectal cancer; lncRNA, long non-coding RNA. 
Table I. Top 10 differentially expressed mRNAs following treatment with polyphyllin VII.

\begin{tabular}{|c|c|c|c|c|}
\hline Gene symbol & Polyphyllin VII & Control & Fold-change & ANOVA P-value \\
\hline HSPA1B & 11.14 & 12.98 & -3.57 & $1.86 \times 10^{-3}$ \\
\hline $\mathrm{ADM}$ & 7.87 & 9.69 & -3.54 & $3.94 \times 10^{-4}$ \\
\hline HSPA1A & 9.52 & 11.17 & -3.14 & $1.11 \times 10^{-3}$ \\
\hline HSPH1 & 11.32 & 12.74 & -2.69 & $1.64 \times 10^{-4}$ \\
\hline SLC38A1 & 12.71 & 14.09 & -2.60 & $6.41 \times 10^{-5}$ \\
\hline KLF7 & 12.35 & 11.16 & 2.28 & $1.90 \times 10^{-2}$ \\
\hline MSL1 & 9.60 & 8.39 & 2.31 & $1.67 \times 10^{-2}$ \\
\hline KRTAP2-2 & 12.94 & 11.63 & 2.47 & $3.96 \times 10^{-3}$ \\
\hline KBTBD3 & 5.48 & 4.14 & 2.54 & $1.62 \times 10^{-2}$ \\
\hline TAS2R30 & 7.83 & 6.27 & 2.95 & $3.10 \times 10^{-2}$ \\
\hline
\end{tabular}

Table II. Top 10 differentially expressed long non-coding RNAs following treatment with polyphyllin VII.

\begin{tabular}{lcccc}
\hline Gene symbol & Polyphyllin VII & Control & Fold-change & ANOVA P-value \\
\hline RNU6-175P & 6.10 & 7.88 & -3.44 & $2.72 \times 10^{-3}$ \\
LDHAP5 & 7.20 & 8.82 & -3.07 & $9.78 \times 10^{-3}$ \\
UCA1 & 13.06 & 14.56 & -2.82 & $2.70 \times 10^{-5}$ \\
RPS27P18 & 3.84 & 5.20 & -2.57 & $2.63 \times 10^{-3}$ \\
RP11-84C10.3 & 5.24 & 6.59 & -2.55 & $1.03 \times 10^{-2}$ \\
AC114498.1 & 11.13 & 9.62 & 2.85 & $2.46 \times 10^{-2}$ \\
ADAM20P1 & 7.04 & 5.52 & 2.88 & $6.81 \times 10^{-3}$ \\
AC069063.1 & 7.32 & 5.768 & 2.95 & $2.54 \times 10^{-2}$ \\
RP11-255C15.3 & 5.10 & 3.53 & 2.96 & $9.51 \times 10^{-3}$ \\
RP11-53019.3 & 7.97 & 5.93 & 4.12 & $4.45 \times 10^{-3}$ \\
\hline
\end{tabular}

A

B
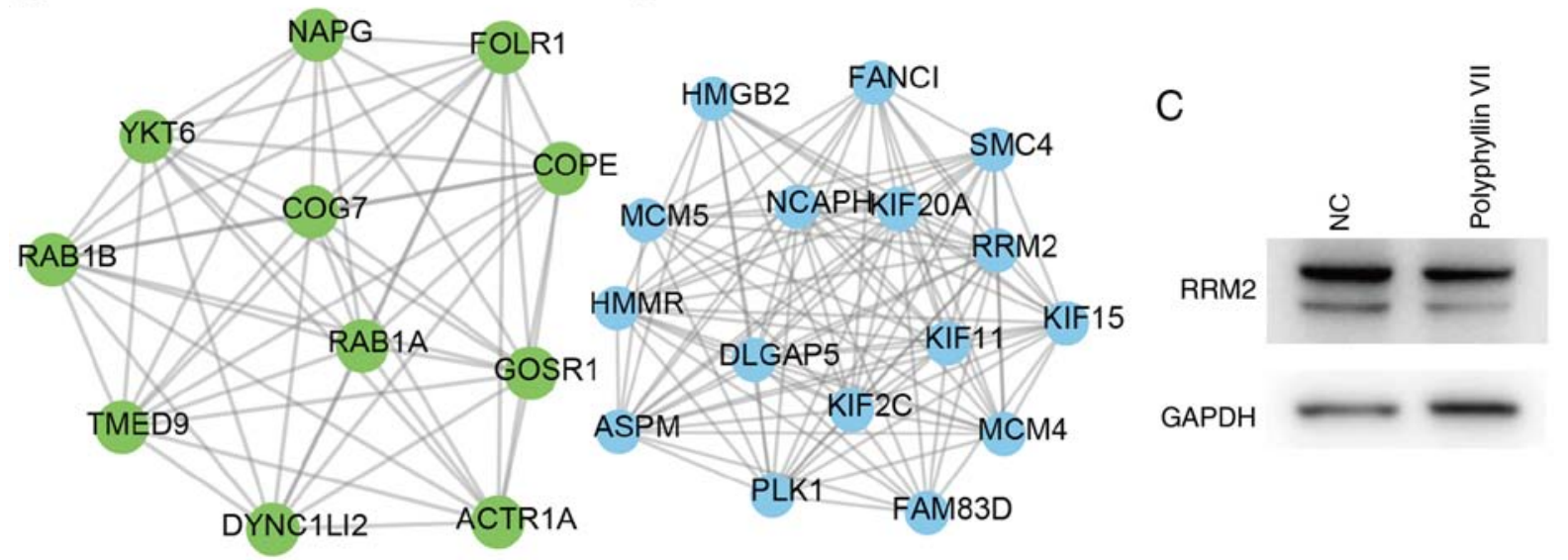

Figure 5. Construction of PPI networks of polyphyllin VII targets in CRC. (A) Construction of key polyphyllin VII upregulated PPI network A in CRC (B) Construction of key polyphyllin VII downregulated PPI network B in CRC. (C) The protein expression levels of RRM2 were detected in HCT116 cells following polyphyllin VII treatment. PPI, Protein-Protein Interaction; CRC, colorectal cancer; RRM2, ribonucleoside-diphosphate reductase subunit M2; NC, negative control.

PPI network analysis of polyphyllin VII-regulated genes in $C R C$. Based on the STRING database (18), PPI networks were constructed for polyphyllin VII-induced and reduced genes in CRC. Following the construction of the PPI network, hub PPI networks were identified using the MCODE plugin (degree cut-off $\geq 2$ and nodes with edges $\geq 2$-core). The top polyphyllin VII-induced hub modules (module A) and top polyphyllin VII-reduced hub modules (module B) are shown in Fig. 5. Module 
A
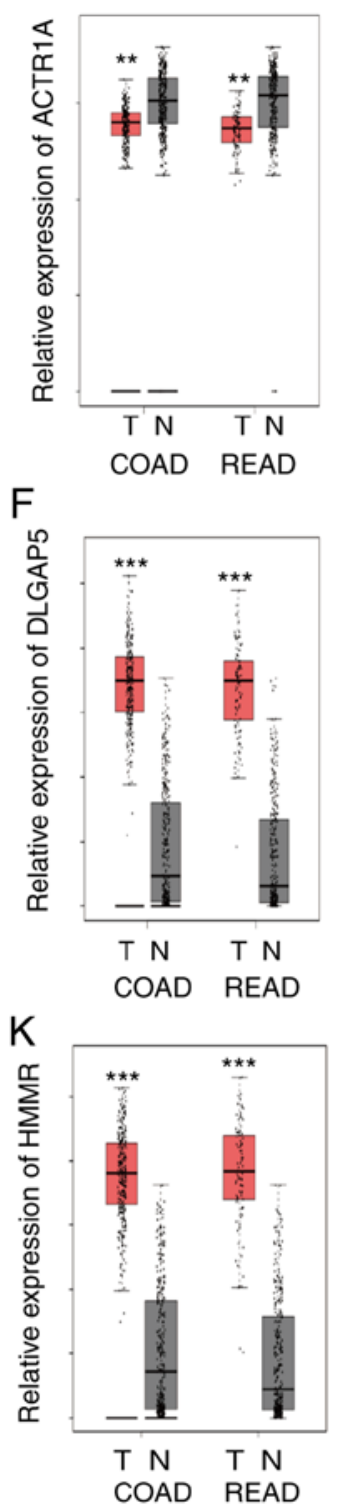

$\mathrm{P}$

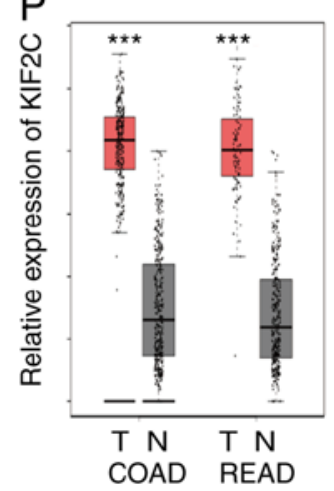

B

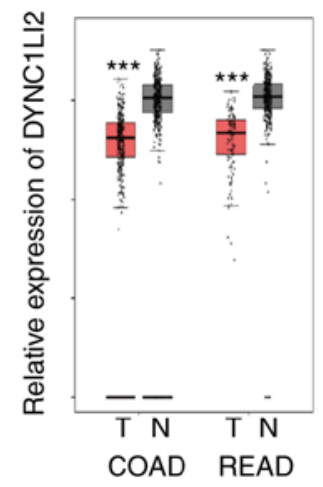

G
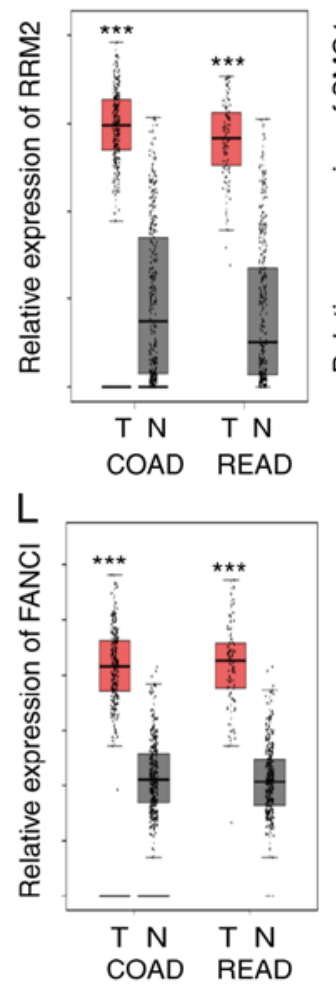

Q

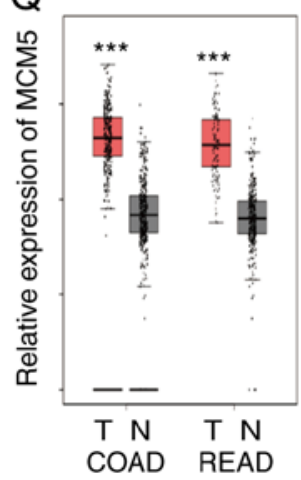

C

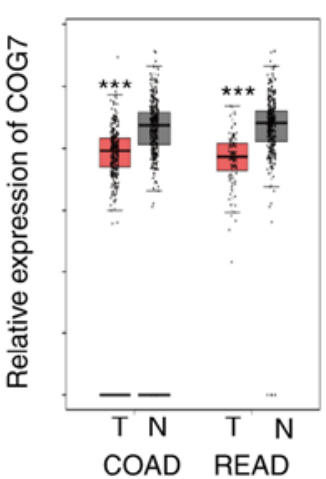

$\mathrm{H} \quad \mathrm{I}$
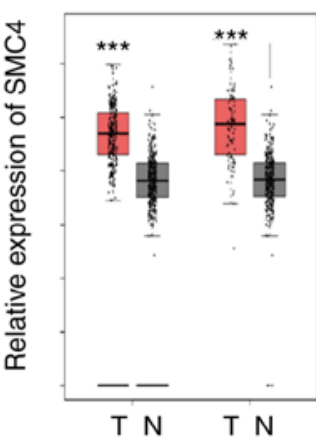

COAD READ

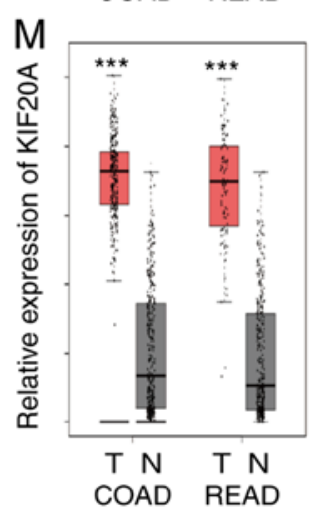

D
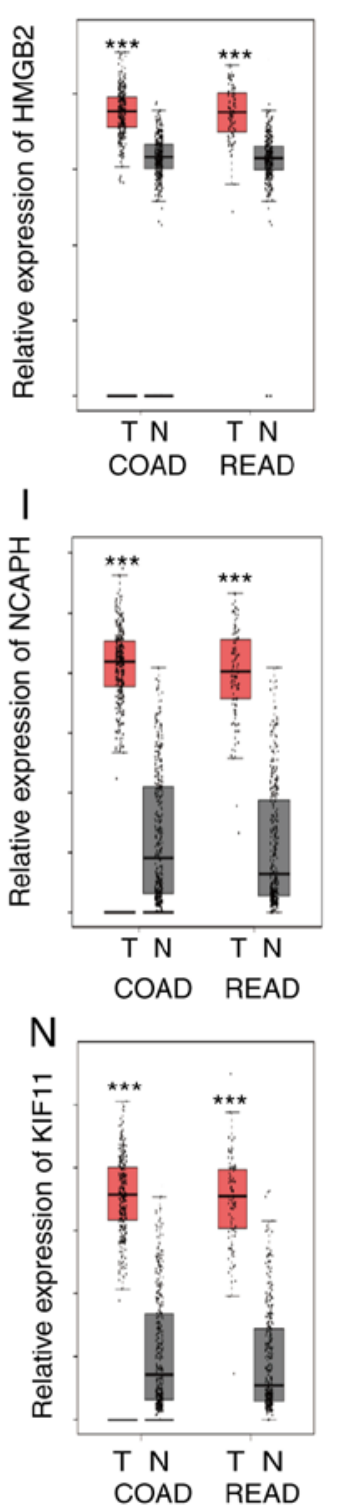

E
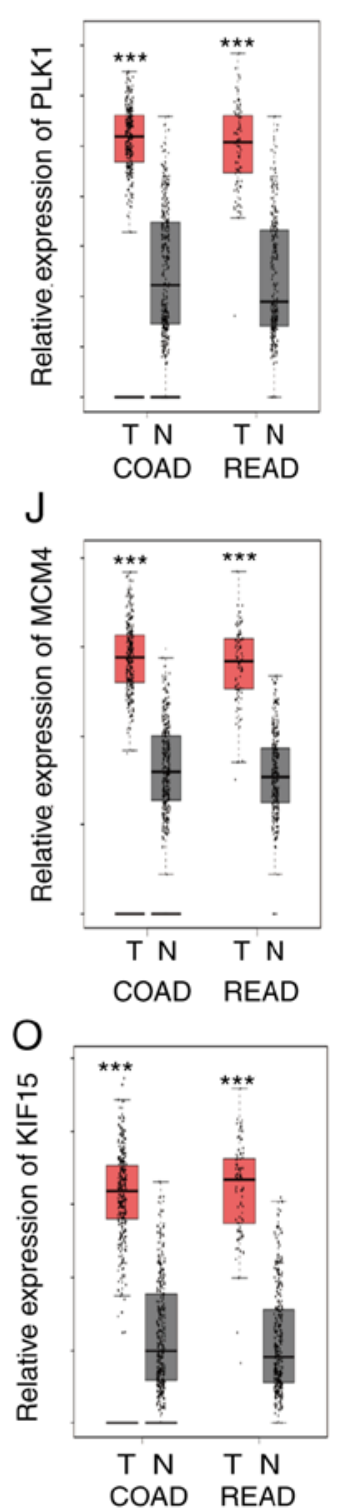

Figure 6. Polyphyllin VII target genes are dysregulated in CRC samples. (A) ACTR1A, (B) DYNC1LI2 and (C) COG7 were downregulated in COAD and READ samples compared with normal tissues. (D) HMGB2, (E) PLK1, (F) DLGAP5, (G) RRM2, (H) SMC4, (I) NCAPH, (J) MCM4, (K) HMMR, (L) FANCI, (M) KIF20A, (N) KIF11, (O) KIF15, (P) KIF2C and (Q) MCM5 were upregulated in COAD and READ samples compared with normal tissues. ${ }^{* *} \mathrm{P}<0.01$ and ${ }^{* * *} \mathrm{P}<0.001$ vs. normal tissue. $\mathrm{N}$, normal; $\mathrm{T}$, tumor; COAD, colon adenocarcinoma; READ, rectum adenocarcinoma.

A contained 11 nodes and 53 edges, including RAB1B, RAB1A, TMED9, YKT6, COG7, GOSR1, NAPG, FOLR1, COPE, DYNC1LI2 and ACTR1A (Fig. 5A). Module B contained 16 nodes and 106 edges, including ASPM, PLK1, HMGB2, KIF2C,
KIF15, FAM83D, KIF11, KIF20A, FANCI, HMMR, MCM5, MCM4, NCAPH, SMC4, RRM2 and DLGAP5 (Fig. 5B). In order to confirm the effects of polyphyllin VII on these proteins, the protein expression levels of SMC4 and RRM2 were detected 
in HCT116 cells following polyphyllin VII treatment. The results showed that Polyphyllin VII treatment led to a notable decrease of SMC4 (Fig. 2G) and RRM2 (Fig. 5C).

Key polyphyllin VII-regulated genes are dysregulated in $C R C$. To explore the clinical implication of key polyphyllin VII-regulated genes in CRC, their expression levels in CRC samples were analyzed using the GEPIA database. As shown in Fig. 6, the results showed that ACTR1A (Fig. 6A), DYNC1LI2 (Fig. 6B) and COG7 (Fig. 6C) were significantly downregulated in both COAD and READ samples compared with normal tissues. Whereas, HMGB2 (Fig. 6D), PLK1 (Fig. 6E), DLGAP5 (Fig. 6F), RRM2 (Fig. 6G), SMC4 (Fig. 6H), NCAPH (Fig. 6I), MCM4 (Fig. 6J), HMMR (Fig. 6K), FANCI (Fig. 6L), KIF20A (Fig. 6M), KIF11 (Fig. 6N), KIF15 (Fig. 6O), KIF2C (Fig. 6P) and MCM5 (Fig. 6Q) were significantly upregulated in COAD and READ samples compared with normal tissues.

\section{Discussion}

There is an urgent need to identify novel anticancer drugs for CRC. In the past decades, multiple studies demonstrated that natural herbal products could be promising novel chemotherapeutics for the treatment of human cancers. Various herbal products were found to exhibit anticancer activity by suppressing cell proliferation and metastasis and inducing cell apoptosis and autophagy (23-25). Previous studies reported that polyphyllin could suppress the progression of multiple human cancers, including lung (26), gastric (27), breast (28) and prostate (29) cancer. Polyphyllin exerts its roles in cancers by inducing tumor cell apoptosis (30), suppressing tumor cell proliferation (31), angiogenesis (32) and reversing multidrug resistance of tumor cells $(33,34)$. Exploring the antitumor effect of polyphyllin could provide novel drugs for CRC treatment.

The anticancer effects of polyphyllin VII has been demonstrated in a number of cancers. The results showed that polyphyllin VII could induce cancer cell apoptosis via regulating caspase protein activation in oral cancer (30). Several recent studies demonstrated that polyphyllin VII could induce the autophagy process in tumor cells $(11,30,35)$. Distant metastasis is the primary cause of cancer-related deaths. Wang et al (36) reported that polyphyllin VI could suppress breast cancer invasion, suggesting the anti-metastatic roles of polyphyllin. The present study revealed that polyphyllin VII could significantly inhibit CRC proliferation, and induce cell cycle arrest and CRC cell apoptosis. A notable increase of cleaved caspase- 3 and Bax expression was also observed. These results were consistent with previous reports $(11,12,30)$. Moreover, the anti-metastatic effects of polyphyllin VII in CRC cells were validated. These results suggested that polyphyllin VII could be a potential antitumor drug for CRC.

Recently,emerging studies have demonstrated that lncRNAs play crucial roles in human cancer progression $(37,38)$. In CRC, it has been reported that lncRNAs are involved in regulating tumor proliferation, metastasis and therapeutic resistance. The IncRNA CALIC was found to promote CRC metastasis via upregulating AXL receptor tyrosine kinase (39). SNHG6 was revealed to suppress CRC cell proliferation and metastasis by targeting ETS proto-oncogene 1 transcription factor (40). To the best of our knowledge, the present study, for the first time, identified 347 upregulated lncRNAs and 1,765 downregulated lncRNAs following polyphyllin VII treatment in CRC cells. Several well-known lncRNAs, such as UCA1 (41), NEAT1 (42), and MALAT1 (43) were identified to be polyphyllin VII targets. UCA1 was previously found to be overexpressed in both CRC tissues and plasma samples, and its expression was correlated with shorter survival times, which suggested that UCA1 could be a potential biomarker for CRC (41). Knockdown of UCA1 suppressed CRC migration and epithelial-mesenchymal transition, and enhanced the radiosensitivity of CRC cells (44). Cui et al (41) found that UCA1 regulated CRC progression via sponging microRNA (miR)-28-5p. NEAT1 promoted CRC progression via activating cell division protein kinase 6 (42). MALAT1 was upregulated in CRC samples. A previous study reported that MALAT1 served as an oncogene in CRC by promoting invasion and metastasis (45). These results suggested that lncRNAs may also play a crucial role in regulating the antitumor effects of polyphyllin VII in CRC.

Moreover, the present study found that polyphyllin VII affected a series of cancer-related pathways, including 'ER to Golgi vesicle-mediated transport', 'regulation of cellular response to heat', 'response to cAMP', 'Ras protein signal transduction', 'metabolic pathways', 'MAPK signaling pathway', 'cell cycle', 'ErbB signaling pathway' and 'TNF signaling pathway'. These pathways are associated with the tumorigenesis and development of CRC. For example, the p38 $\alpha$ /MAPK pathway promotes cell metabolism, invasion, autophagy, inflammation and angiogenesis in CRC and has been validated as a key factor in CRC therapy and chemoresistance (46). The abnormal regulation of the cell cycle plays a crucial role in promoting tumor growth. Moreover, in the present study, a PPI network was constructed to identify key polyphyllin VII-regulated genes in CRC. Two hub networks regulated by polyphyllin VII were revealed in this study. A series of genes, such as RAB1B, RAB1A, TMED9, YKT6, COG7, GOSR1, NAPG, FOLR1, COPE, DYNC1LI2, ACTR1A, ASPM, PLK1, HMGB2, KIF2C, KIF15, FAM83D, KIF11, KIF20A, FANCI, HMMR, MCM5, MCM4, NCAPH, SMC4, RRM2 and DLGAP5, were regarded as key regulators. Moreover, polyphyllin VII-regulated genes were significantly overexpressed in CRC samples compared with normal tissues. Among these genes, RRM2, SMC4 and MCM4 have been reported to play a regulatory role in CRC proliferation and migration. In the present study, polyphyllin VII treatment led to a significant decrease of RRM2 and SMC4 expression. Overexpression of RRM2 is correlated with poor survival in patients with CRC (47). SMC4 could predict survival and serve as a therapeutic target for CRC (48).

In summary, the present demonstrated that polyphyllin VII suppressed CRC proliferation and migration, but induced apoptosis and cell cycle arrest. Microarray analysis identified that polyphyllin VII could affect multiple protein-coding genes and non-coding RNAs. Bioinformatics analysis revealed that polyphyllin VII regulated multiple pathways in CRC, including 'ER to Golgi vesicle-mediated transport', 'response to cAMP', 'Ras protein signal transduction', 'metabolic pathways', 'MAPK signaling pathway' and 'cell cycle'. PPI 
networks analysis identified RRM2, SMC4 and MCM4 as the key targets of polyphyllin VII in CRC. Finally, the results demonstrated that these key polyphyllin VII-regulated genes were dysregulated in CRC. Taken together, these results indicated that polyphyllin VII could be a novel antitumor drug for the treatment of CRC.

\section{Acknowledgements}

Not applicable.

\section{Funding}

This work was supported by the Natural Science Foundation of Hunan Province (grant no. 2018JJ3312), Hunan Health Committee for Scientific Research Projects (grant no. C2019067), Academic Topics of Hunan Academy of Traditional Chinese Medicine (grant no. 201701), the Changsha Science and Technology Bureau (grant no. kq1907124) and the Department of Education of Hunan Province (grant no. 19b432).

\section{Availability of data and materials}

The datasets used and/or analyzed during the current study are available from the corresponding author on reasonable request.

\section{Authors' contributions}

CS and WT designed the study. CS, BP and XY performed the experiments. CS wrote the paper. CS and BP conducted statistical analysis and interpreted the data. CS, BP, XY and WT reviewed and edited the manuscript. All authors read and approved the final version of the manuscript.

\section{Ethics approval and consent to participate}

Not applicable.

\section{Patient consent for publication}

Not applicable.

\section{Competing interests}

The authors declare that they have no competing interests.

\section{References}

1. Chakradhar S: Colorectal cancer: 5 big questions. Nature 521: S16, 2015.

2. Brody H: Colorectal cancer. Nature 521: S1, 2015.

3. Rawla P, Sunkara T and Barsouk A: Epidemiology of colorectal cancer: Incidence, mortality, survival, and risk factors. Prz Gastroenterol 14: 89-103, 2019.

4. Andre T, Boni C, Mounedji-Boudiaf L, Navarro M, Tabernero J, Hickish T, Topham C, Zaninelli M, Clingan P, Bridgewater J, et al: Oxaliplatin, fluorouracil, and leucovorin as adjuvant treatment for colon cancer. N Engl J Med 350: 2343-2351, 2004.

5. Teng WJ, Chen P, Zhu FY, Di K, Zhou C, Zhuang J, Cao XJ, Yang J, Deng LJ and Sun CG: Effect of Rhizoma paridis total saponins on apoptosis of colorectal cancer cells and imbalance of the JAK/STAT3 molecular pathway induced by IL-6 suppression. Genet Mol Res 14: 5793-5803, 2015.
6. Attar R, Tabassum S, Fayyaz S, Ahmad MS, Nogueira DR, Yaylim I, Timirci-Kahraman O, Kucukhuseyin O, Cacina C, Farooqi AA and Ismail M: Natural products are the future of anticancer therapy: Preclinical and clinical advancements of viscum album phytometabolites. Cell Mol Biol (Noisy-le-Grand) 61: 62-68, 2015.

7. da Rocha AB, Lopes RM and Schwartsmann G: Natural products in anticancer therapy. Curr Opin Pharmacol 1: 364-369, 2001.

8. Zhang C, Li C, Jia X, Wang K, Tu Y, Wang R, Liu K, Lu T and He C: In vitro and in vivo anti-inflammatory effects of polyphyllin VII through downregulating MAPK and NF-kB pathways. Molecules 24: 875, 2019.

9. Wu Z, Zhang J, Xu F, Wang Y and Zhang J: Rapid and simple determination of polyphyllin I, II, VI, and VII in different harvest times of cultivated Paris polyphylla Smith var. yunnanensis (Franch.) Hand.-Mazz by UPLC-MS/MS and FT-IR. J Nat Med 71: 139-147, 2017.

10. Lin Z, Liu Y, Li F, Wu J, Zhang G, Wang Y, Lu L and Liu Z: Anti-lung cancer effects of polyphyllin VI and VII potentially correlate with apoptosis in vitro and in vivo. Phytother Res 29: 1568-1576, 2015.

11. Chen JC, Hsieh MJ, Chen CJ, Lin JT, Lo YS, Chuang YC, Chien SY and Chen MK: Polyphyllin G induce apoptosis and autophagy in human nasopharyngeal cancer cells by modulation of AKT and mitogen-activated protein kinase pathways in vitro and in vivo. Oncotarget 7: 70276-70289, 2016.

12. Zhang C, Jia X, Bao J, Chen S, Wang K, Zhang Y, Li P, Wan JB, Su H, Wang Y, et al: Polyphyllin VII induces apoptosis in HepG2 cells through ROS-mediated mitochondrial dysfunction and MAPK pathways. BMC Complement Altern Med 16: 58, 2016.

13. Yang F, Liu H, Zhao J, Ma X and Qi W: POLR1B is upregulated and promotes cell proliferation in non-small cell lung cancer. Oncol Lett 19: 671-680, 2020.

14. Ritchie ME, Phipson B, Wu D, Hu Y, Law CW, Shi W and Smyth GK: Limma powers differential expression analyses for RNA-sequencing and microarray studies. Nucleic Acids Res 43: e47, 2015.

15. Dennis G Jr, Sherman BT, Hosack DA, Yang J, Gao W, Lane HC and Lempicki RA: DAVID: Database for annotation, visualization, and integrated discovery. Genome Biol 4: P3, 2003.

16. Ashburner M, Ball CA, Blake JA, Botstein D, Butler $\mathrm{H}$, Cherry JM, Davis AP, Dolinski K, Dwight SS, Eppig JT, et al: Gene ontology: Tool for the unification of biology. The gene ontology consortium. Nat Genet 25: 25-29, 2000.

17. Kanehisa M and Goto S: KEGG: Kyoto encyclopedia of genes and genomes. Nucleic Acids Res 28: 27-30, 2000.

18. Szklarczyk D, Franceschini A, Wyder S, Forslund K, Heller D, Huerta-Cepas J, Simonovic M, Roth A, Santos A, Tsafou KP, et al: STRING v10: Protein-protein interaction networks, integrated over the tree of life. Nucleic Acids Res 43: D447-D452, 2015.

19. Chin $\mathrm{CH}$, Chen $\mathrm{SH}, \mathrm{Wu} \mathrm{HH}, \mathrm{Ho} \mathrm{CW}, \mathrm{Ko} \mathrm{MT}$ and Lin $\mathrm{CY}$ : CytoHubba: Identifying hub objects and sub-networks from complex interactome. BMC Syst Biol 8 (Suppl 4): S11, 2014.

20. Minguez P, Letunic I, Parca L and Bork P: PTMcode: A database of known and predicted functional associations between post-translational modifications in proteins. Nucleic Acids Res 41: D306-D311, 2013.

21. Shannon P, Markiel A, Ozier O, Baliga NS, Wang JT, Ramage D, Amin N, Schwikowski B and Ideker T: Cytoscape: A software environment for integrated models of biomolecular interaction networks. Genome Res 13: 2498-2504, 2003.

22. Tang Z, Li C, Kang B, Gao G, Li C and Zhang Z: GEPIA: A web server for cancer and normal gene expression profiling and interactive analyses. Nucleic Acids Res 45: W98-W102, 2017.

23. Tsai YT, Lai JN, Lo PC, Chen CN and Lin JG: Prescription of Chinese herbal products is associated with a decreased risk of invasive breast cancer. Medicine (Baltimore) 96: e7918, 2017.

24. Sparber A, Jonas W, White J, Derenzo E, Johnson E and Bergerson S: Cancer clinical trials and subject use of natural herbal products. Cancer Invest 18: 436-439, 2000.

25. Spaulding-Albright N: A review of some herbal and related products commonly used in cancer patients. J Am Diet Assoc 97 (Suppl 10): S208-S215, 1997.

26. Wu Y, Si Y, Xiang Y, Zhou T, Liu X, Wu M, Li W, Zhang T, Xiang K, Zhang L, et al: Polyphyllin I activates AMPK to suppress the growth of non-small-cell lung cancer via induction of autophagy. Arch Biochem Biophys 687: 108285, 2020. 
27. Dong R, Guo J, Zhang Z, Zhou Y and Hua Y: Polyphyllin I inhibits gastric cancer cell proliferation by downregulating the expression of fibroblast activation protein alpha (FAP) and hepatocyte growth factor (HGF) in cancer-associated fibroblasts. Biochem Biophys Res Commun 497: 1129-1134, 2018

28. He DX, Li GH, Gu XT, Zhang L, Mao AQ, Wei J, Liu DQ, Shi GY and Ma X: A new agent developed by biotransformation of polyphyllin VII inhibits chemoresistance in breast cancer. Oncotarget 7: 31814-31824, 2016.

29. Zhang D, Liu S, Liu Z, Ma C, Jiang Y, Sun C, Li K, Cao G, Lin Z, Wang P, et al: Polyphyllin I induces cell cycle arrest in prostate cancer cells via the upregulation of IL6 and P21 expression. Medicine (Baltimore) 98: e17743, 2019.

30. Hsieh MJ, Chien SY, Lin JT, Yang SF and Chen MK: Polyphyllin $\mathrm{G}$ induces apoptosis and autophagy cell death in human ora cancer cells. Phytomedicine 23: 1545-1554, 2016.

31. Hong F, Gu W, Jiang J, Liu X and Jiang H: Anticancer activity of polyphyllin I in nasopharyngeal carcinoma by modulation of lncRNA ROR and P53 signalling. J Drug Target 27: 806-811, 2019.

32. Yang M, Zou J, Zhu H, Liu S, Wang H, Bai P and Xiao X: Paris saponin II inhibits human ovarian cancer cell-induced angiogenesis by modulating NF-kB signaling. Oncol Rep 33: 2190-2198, 2015.

33. Lou W, Chen Y, Zhu KY, Deng H, Wu T and Wang J: Polyphyllin I overcomes EMT-associated resistance to erlotinib in lung cancer cells via IL-6/STAT3 pathway inhibition. Biol Pharm Bull 40: 1306-1313, 2017.

34. Zheng R, Jiang H, Li J, Liu X and Xu H: Polyphyllin II restores sensitization of the resistance of PC-9/ZD cells to gefitinib by a negative regulation of the PI3K/Akt/mTOR signaling pathway. Curr Cancer Drug Targets 17: 376-385, 2017.

35. Cui J, Man S, Cui N, Yang L, Guo Q, Ma L and Gao W: The synergistic anticancer effect of formosanin $\mathrm{C}$ and polyphyllin VII based on caspase-mediated cleavage of Beclin1 inhibiting autophagy and promoting apoptosis. Cell Prolif 52: e12520, 2019.

36. Wang P, Yang Q, Du X, Chen Y and Zhang T: Targeted regulation of Rell2 by microRNA-18a is implicated in the anti-metastatic effect of polyphyllin VI in breast cancer cells. Eur J Pharmacol 851: 161-173, 2019.

37. Joung J, Engreitz JM, Konermann S, Abudayyeh OO, Verdine VK, Aguet F, Gootenberg JS, Sanjana NE, Wright JB, Fulco CP, et al: Genome-scale activation screen identifies a lncRNA locus regulating a gene neighbourhood. Nature 548: 343-346, 2017.

38. Parikshak NN, Swarup V, Belgard TG, Irimia M, Ramaswami G, Gandal MJ, Hartl C, Leppa V, Ubieta LT, Huang J, et al: Genome-wide changes in lncRNA, splicing, and regional gene expression patterns in autism. Nature 540: 423-427, 2016.
39. Kawasaki Y, Miyamoto M, Oda T, Matsumura K, Negishi L, Nakato R, Suda S, Yokota N, Shirahige K and Akiyama T: The novel lncRNA CALIC upregulates AXL to promote colon cancer metastasis. EMBO Rep 20: e47052, 2019.

40. Meng S, Jian Z, Yan X, Li J and Zhang R: LncRNA SNHG6 inhibits cell proliferation and metastasis by targeting ETS1 via the PI3K/AKT/mTOR pathway in colorectal cancer. Mol Med Rep 20: 2541-2548, 2019.

41. Cui M, Chen M, Shen Z, Wang R, Fang X and Song B: LncRNA-UCA1 modulates progression of colon cancer through regulating the miR-28-5p/HOXB3 axis. J Cell Biochem: Jan 16 , 2019 (Epub ahead of print).

42. He Z, Dang J, Song A, Cui X, Ma Z and Zhang Z: NEAT1 promotes colon cancer progression through sponging miR-495-3p and activating CDK6 in vitro and in vivo. J Cell Physiol 234: 19582-19591, 2019.

43. Wu Q, Meng WY, Jie Y and Zhao H: LncRNA MALAT1 induces colon cancer development by regulating miR-129-5p/HMGB1 axis. J Cell Physiol 233: 6750-6757, 2018.

44. Yang X, Liu W, Xu X, Zhu J, Wu Y, Zhao K, He S, Li M, Wu Y, Zhang S, et al: Downregulation of long noncoding RNA UCA1 enhances the radiosensitivity and inhibits migration via suppression of epithelialmesenchymal transition in colorectal cancer cells. Oncol Rep 40: 1554-1564, 2018.

45. Ji Q, Cai G, Liu X, Zhang Y, Wang Y, Zhou L, Sui H and Li Q: MALAT1 regulates the transcriptional and translational levels of proto-oncogene RUNX2 in colorectal cancer metastasis. Cell Death Dis 10: 378, 2019.

46. Braicu C, Buse M, Busuioc C, Drula R, Gulei D, Raduly L, Rusu A, Irimie A, Atanasov AG, Slaby O, et al: A comprehensive review on MAPK: A promising therapeutic target in cancer. Cancers (Basel) 11: 1618, 2019.

47. Yoshida Y, Tsunoda T, Doi K, Tanaka Y, Fujimoto T, Machida T, Ota T,Koyanagi M, Takashima Y, Sasazuki T,etal:KRAS-mediated up-regulation of RRM2 expression is essential for the proliferation of colorectal cancer cell lines. Anticancer Res 31: 2535-2539, 2011.

48. Li X, Chen W, Jia J, You Z, Hu C, Zhuang Y, Lin Z, Liu Y, Yang C and $\mathrm{Xu} \mathrm{R}$ : The long non-coding RNA-RoR promotes the tumorigenesis of human colorectal cancer by targeting miR-6833-3p through SMC4. Onco Targets Ther 13: 2573-2581, 2020.

This work is licensed under a Creative Commons Attribution-NonCommercial-NoDerivatives 4.0 International (CC BY-NC-ND 4.0) License. 